\title{
Analgesic therapy improves arterial endothelial function following non-cardiovascular surgery: A randomized, placebo-controlled trial
}

\author{
MENG-JUN WU ${ }^{1 *}$, MENG-CHANG YANG $^{2 *}$, LONG-QING RAN $^{1 *}$, SU-MEI WEI ${ }^{3 *}$, \\ WEN-LAI ZHOU ${ }^{4}$, YONG-SHENG GOU ${ }^{5}$ and HAI YU ${ }^{6}$
}

\begin{abstract}
${ }^{1}$ Department of Anesthesiology, Chengdu Women and Children's Central Hospital, Chongqing Medical University; ${ }^{2}$ Department of Anesthesiology, Sichuan Provincial People's Hospital; ${ }^{3}$ Department of Obstetrics, Chengdu Women and Children's Central Hospital, Chongqing Medical University, Chengdu, Sichuan 610041; ${ }^{4}$ Department of Intensive Care Unit, Dazhou Central Hospital, Dazhou, Sichuan 635000; ${ }^{5}$ Department of Orthopedics, Shuangliu First People's Hospital, Chengdu, Sichuan 610200; ${ }^{6}$ Department of Anesthesiology, West China Hospital, Sichuan University, Chengdu, Sichuan 610041, P.R. China
\end{abstract}

Received December 19, 2016; Accepted July 11, 2017

DOI: $10.3892 / \mathrm{etm} .2017 .5139$

\begin{abstract}
Pain subsequent to non-cardiac surgery may affect the endothelial function, which in turn contributes to myocardial injury (MI). The present study examined whether effective pain control is able to improve the postoperative endothelial function. Patients $(n=160)$ undergoing laparoscopic cholecystectomy were randomly assigned into two groups, treated with tramadol analgesic or saline (placebo) following surgery. On preoperative day 1 (baseline) and postoperatively at $2 \mathrm{~h}$, 1 day and 5 days, pain was assessed on a visual analogue scale (VAS), and B-mode ultrasound was used to measure brachial endothelium-dependent flow-mediated dilation (FMD) and nitroglycerin-induced dilation. At $2 \mathrm{~h}$ postoperatively, the FMD in the two groups was significantly lower compared with that at the other three time points $(\mathrm{P} \leq 0.005)$, while VAS was significantly higher $(\mathrm{P}<0.05)$. Patients in the tramadol group presented significantly reduced VAS values in comparison with those in the placebo group at $2 \mathrm{~h}$ and 1 day postoperatively $(\mathrm{P}=0.013$ and 0.031 , respectively), as well as significantly higher FMD at 2 h $(6.7 \pm 1.5$ vs. $6.0 \pm 1.7 \% ; \mathrm{P}=0.001)$ and 1 day
\end{abstract}

Correspondence to: Dr Hai Yu, Department of Anesthesiology, West China Hospital, Sichuan University, 37 Huangmen Street, Chengdu, Sichuan 610041, P.R. China

E-mail: yuhaishan117@yahoo.com

Dr Wen-Lai Zhou, Department of Intensive Care Unit, Dazhou Central Hospital, 56 Nanyuemiao Street, Dazhou, Sichuan 635000, P.R. China

E-mail: mengjunwoo@163.com

*Contributed equally

Key words: endothelial dysfunction, postoperative pain, analgesic therapy, myocardial injury, laparoscopic cholecystectomy postoperatively $(7.3 \pm 1.3$ vs. $6.9 \pm 1.4 \% ; \mathrm{P}=0.03)$. A VAS score of $<5$ was independently associated with postoperative FMD of $\geq 7$ (odds ratio, $2.5 ; 95 \%$ confidence interval, 1.0-6.0; $\mathrm{P}=0.047$ ). Backward multivariate linear regression also demonstrated that FMD was independently correlated with age and VAS score $(\mathrm{B}=-1.403, \mathrm{P}=0.011 ; \mathrm{B}=-0.579, \mathrm{P}=0.003)$. The response to nitroglycerin-induced dilation remained stable in all patients at baseline and at all postoperative time points. In conclusion, analgesic treatment may improve the arterial endothelial function following non-cardiac surgery, which may help prevent postoperative MI.

\section{Introduction}

Myocardial injury (MI) following non-cardiac surgery is a significant international public health concern, occurring in $\sim 8 \%$ of such surgeries and causing mortality in $10 \%$ of affected patients within 30 days of surgery (1). The pathophysiology of perioperative MI remains poorly understood, and reliable methods do not yet exist to predict the risk of such injury in individual patients $(2,3)$.

MI subsequent to non-cardiac surgery may be caused by preoperative endothelial dysfunction, with $\sim 58 \%$ of patients with this dysfunction developing postoperative MI (4). Endothelial dysfunction compromises the proper regulation of vascular tone, thrombosis and inflammation (5), and increases the risk of atherosclerosis and thromboembolic events (6). Coronary artery endothelial dysfunction increases the risk of adverse cardiovascular events $(2,7,8)$, and preoperative brachial arterial endothelial dysfunction is independently predictive of short- and long-term postoperative cardiovascular events in patients undergoing vascular surgery $(9,10)$. Perioperative endothelial dysfunction may be a risk factor for postoperative cardiovascular events, and assessment of endothelial function using non-invasive measures prior to and following non-cardiac surgery may assist clinicians to prevent and treat postoperative MI (4). 
Postoperative pain may impair the endothelial function and increase the risk of endothelial dysfunction, consequently leading to acute coronary syndrome (11). In addition, pain is negatively correlated with perioperative endothelial function (11). This raises the question of whether appropriate pain management following non-cardiac surgery is able to reduce the risk of endothelial dysfunction. In support of this hypothesis, postoperative pain management, such as the epidural blockade of thoracic sympathetic segments using local anesthetics, has been demonstrated to reduce risk of MI (12-15).

To test the hypothesis that postoperative pain control may help reduce endothelial dysfunction, a randomized controlled investigation was performed in the present study, comparing the analgesic effects of tramadol against a placebo. The results may help guide clinical practices for reducing the risk of MI subsequent to non-cardiac surgery and may help clarify the poorly understood mechanisms underlying this injury.

\section{Materials and methods}

Subjects. This randomized, double-blind, placebo-controlled study was performed in Chongqing Medical University (Chongqing, China). Patients aged 20-60 years who were undergoing laparoscopic cholecystectomy involving standardized total intravenous anesthesia (TIVA) at Chengdu Women and Children's Central Hospital (Chengdu, China) between January 2014 and November 2015 were eligible to participate in the present study (16). The exclusion criteria were as follows: Patients undergoing emergency surgery; patients classified as grade IV or V on the American Society of Anesthesiologists scale (11); patients declining to be analyzed postoperatively; or patient with unstable postoperative vital signs.

In order to estimate an adequate sample size, it was hypothesized that the placebo group would experience $70 \%$ reduction in the endothelial function, while the tramadol group would experience a $30 \%$ reduction, based on the findings of previous studies on endothelial dysfunction $(17,18)$. Assuming a baseline flow-mediated dilation (FMD) of $7.0 \pm 1.5 \%$, it was calculated that 80 patients in each group should provide $80 \%$ power to detect a change in the FMD at $\alpha=0.05$.

Group allocation and interventions. Patients were assigned to the tramadol or saline (placebo) groups in a 1:1 ratio using software-driven randomization. All subjects completed a questionnaire in order to provide the baseline clinicodemographic data, including the present complaints, as well as personal and family medical history. Pain severity was assessed using a modified visual analogue scale (VAS) (11) with scores between 0 (no pain) and 10 (extremely painful). This scale has demonstrated a test-retest reliability intraclass correlation of 0.87 for repeated scoring (11). Brachial artery FMD and endothelium-independent dilation, which is referred to as the nitroglycerin (NTG)-induced dilation, were measured on preoperative day 1 (baseline).

All participants received intravenous glycopyrrolate (0.2 mg; Carbosynth Ltd., Compton, UK) as premedication, followed by TIVA that was performed as described previously (16). Briefly, TIVA was induced using propofol $(2 \mathrm{mg} / \mathrm{kg}$; Yichang Humanwell Pharmaceutical Co.,Ltd., Yichang, China) and fentanyl $(0.3 \mu \mathrm{g} / \mathrm{kg}$; Yichang Humanwell Pharmaceutical
Co., Ltd.) target-controlled infusions (TCIs), administered using a two-channel infusion pump. Intravenous rocuronium $(0.6 \mathrm{mg} / \mathrm{kg}$; Yichang Humanwell Pharmaceutical Co., Ltd.) was also administered for neuromuscular blockade. Following tracheal intubation, propofol and fentanil TCIs were titrated to maintain the bispectral index between 40-60, and the systolic blood pressure and heart rate within $\pm 20 \%$ of their baseline values. Participants received a single intravenous dose of ondansetron (4 mg, Yichang Humanwell Pharmaceutical Co., Ltd.) to prevent postoperative nausea and vomiting. Routine monitoring consisted of electrocardiography, pulse oximetry, non-invasive arterial pressure, end-tidal carbon dioxide partial pressure and bispectral index measurement.

For postoperative pain management, patients in the tramadol group were administered intravenous, patient-controlled tramadol prior to transporting to the recovery room. The delivery settings were a bolus dose of $10 \mathrm{mg}$ (Yichang Humanwell Pharmaceutical Co., Ltd.), followed by a lock-out time of $10 \mathrm{~min}$ and a basal infusion rate of $10 \mathrm{mg} / \mathrm{h}$. Patients in the placebo group received $0.9 \%$ saline. If VAS scores were $>4$, patients were given intravenous fentanyl $(20 \mu \mathrm{g})$ repeatedly until the score fell $<4$ (19). The number of patients requiring rescue analgesia was recorded. The VAS scores, FMD and NTG-induced dilation were again examined at 2 h, 1 day and 5 days postoperatively.

Measurement of FMD and NTG-induced dilation. The flow-mediated and NTG-induced dilations were both examined in the present study, since these function through different mechanisms. In FMD, increased blood flow stimulates the release of vasodilators, such as nitric oxide, from the endothelium and causes arterial dilation. By contrast, NTG functions directly on the arterial smooth muscle and induces endothelium-independent dilation (11).

The FMD and NTG-induced dilation were measured using ultrasound as previously described $(20,21)$. Briefly, the brachial artery diameter was measured using high-resolution B-mode ultrasound under three conditions: At rest, in response to reactive hyperemia, and following sublingual exposure to nitroglycerin $(400 \mu \mathrm{g})$. An L10-5 linear array transducer with a median frequency of $7.5 \mathrm{MHz}$ and a standard ATL HDI 5,000 ultrasound system (Philips Healthcare, Amsterdam, The Netherlands) were used. Reactive hyperemia was induced by inflating a pneumatic tourniquet around the forearm, which had been positioned distal to the segment of the artery being scanned, to a pressure of $220-240 \mathrm{mmHg}$ for $4.5 \mathrm{~min}$, followed by release. Doppler-derived arterial flow was measured at rest and during hyperemia.

These procedures were conducted in a quiet environment, and no significant alterations in the heart rate or blood pressure were observed. These procedures have been demonstrated to be accurate and reproducible, with a low interobserver error (11). In our previous studies, excellent reliability was routinely achieved, with the FMD presenting a mean relative difference of only $3 \%$ within individual patients $(22,23)$.

All measurement sessions were recorded on Super-VHS videotape for subsequent off-line analysis by an investigator blinded to the subject identity, group allocation and time point (pre- or postoperative). The same investigator analyzed videos of all participants. 
Table I. Clinicodemographic characteristics and indicators of vascular reactivity in patients receiving analgesic or placebo treatment subsequent to laparoscopic cholecystectomy.

\begin{tabular}{|c|c|c|}
\hline Characteristic & Tramadol $(\mathrm{n}=80)$ & Saline $(n=80)$ \\
\hline Age, years & $56.8 \pm 10.1$ & $57.0 \pm 11.2$ \\
\hline Male : female, $\mathrm{n}$ & $28: 32$ & $26: 34$ \\
\hline \multicolumn{3}{|l|}{ Risk classification, $\mathrm{n}$} \\
\hline ASA grade I & 32 & 34 \\
\hline ASA grade II & 28 & 26 \\
\hline Surgical time, min & $65.3 \pm 10.2$ & $64.2 \pm 9.6$ \\
\hline \multicolumn{3}{|l|}{ Laboratory results } \\
\hline $\mathrm{TC}(\mathrm{mmol} / \mathrm{l})$ & $5.23 \pm 0.82$ & $5.31 \pm 1.02$ \\
\hline TG (mmol/l) & $1.72 \pm 1.21$ & $1.68 \pm 0.65$ \\
\hline Urea nitrogen $(\mathrm{mmol} / \mathrm{l})$ & $4.71 \pm 0.73$ & $4.66 \pm 1.15$ \\
\hline Creatinine $(\mathrm{mmol} / \mathrm{l})$ & $74.9 \pm 13.1$ & $75.2 \pm 11.8$ \\
\hline Glucose (mmol/l) & $5.28 \pm 1.10$ & $4.36 \pm 3.01$ \\
\hline \multicolumn{3}{|l|}{ Vascular reactivity } \\
\hline Brachial FMD (\%) & $7.0 \pm 1.5$ & $6.9 \pm 1.4$ \\
\hline $\begin{array}{l}\text { Brachial NTG-induced } \\
\text { dilation }(\%)\end{array}$ & $16.8 \pm 2.3$ & $16.3 \pm 2.7$ \\
\hline Blood flow, ml/min & $23.6 \pm 12.8$ & $20.4 \pm 9.1$ \\
\hline Shear rate, x 103/sec & $81.2 \pm 20.8$ & $86.0 \pm 21.9$ \\
\hline Reactive hyperemia (\%) & $425 \pm 102$ & $417.5 \pm 191.3$ \\
\hline VAS score & $0.8 \pm 1.3$ & $0.6 \pm 1.1$ \\
\hline \multicolumn{3}{|l|}{ Blood pressure (mmHg) } \\
\hline Systolic & $113.1 \pm 15.2$ & $115.4 \pm 17.6$ \\
\hline Diastolic & $71.9 \pm 9.3$ & $72.3 \pm 8.51$ \\
\hline Heart rate (bpm) & $75.3 \pm 6.2$ & $72.1 \pm 9.6$ \\
\hline
\end{tabular}

Values expressed as the mean \pm standard deviation. ASA, American Society of Anesthesiologists; FMD, flow-mediated dilation; NTG, nitroglycerin-induced dilation; TC, total blood cholesterol; TG, triglycerides; VAS, visual analogue scale.

Statistical analysis. Data are expressed as the mean \pm standard deviation. Collected data were evaluated using an analysis of covariance model. Differences in the clinical and vascular parameters were compared with baseline among the three postoperative periods ( $2 \mathrm{~h}, 1$ day, 5 days) and significant differences were determined by repeated-measures analysis of variance. Multiple comparisons between groups were performed using Student-Newman-Keuls post-hoc test. Backward stepwise multivariate analysis of variance with Tukey's post-hoc test was performed to estimate the major determinants of the FMD data, including age, VAS, systolic and diastolic blood pressures, heart rate and reactive hyperemia. Statistical analysis was performed using SPSS software 18.0 (SPSS, Inc., Chicago, IL, USA). $\mathrm{P}<0.05$ was considered to indicate a statistically significant difference.

\section{Results}

Baseline characteristics. A total of 160 patients were enrolled into the current study and randomized into the tramadol

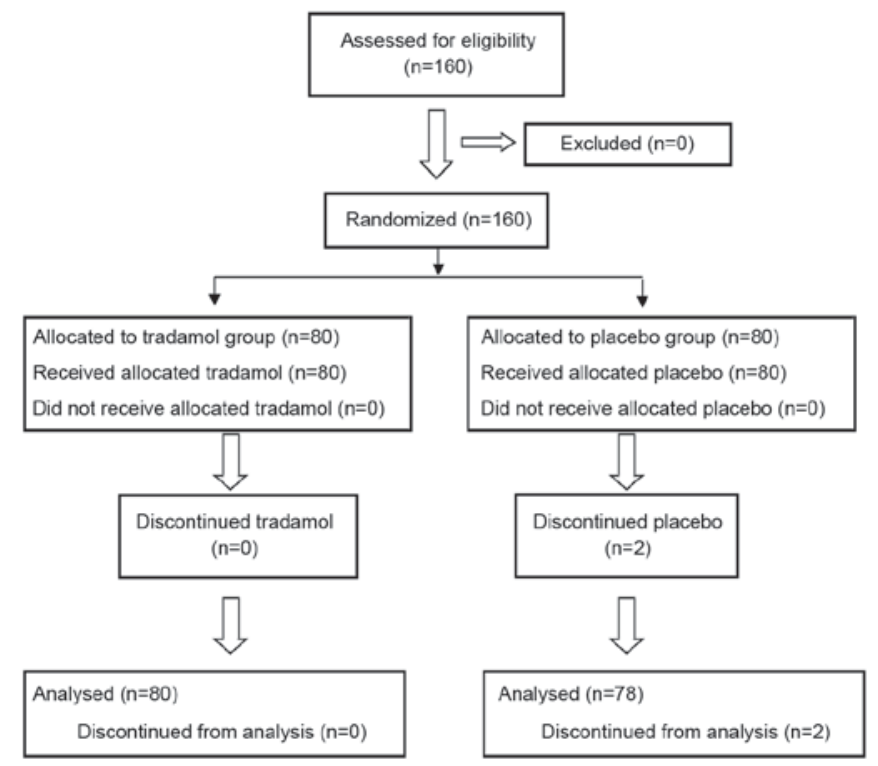

Figure 1. CONSORT flow diagram demonstrating the division of the study participants through each stage of the trial. Two participants in the placebo group were excluded as they had to undergo open cholecystectomy due to dense inflammatory adhesions.

and placebo groups (Fig. 1). However, 2 participants in the placebo group were excluded since they had to undergo open cholecystectomy due to dense inflammatory adhesions. Thus, 158 patients completed the study, with a mean age of 43.8 \pm 14.0 years (range, 20-60 years). The tramadol and placebo groups were similar with regard to their major clinicodemographic characteristics and vascular function indicators (Table I), including the age, body mass index (BMI), pain history, dosage and type of anesthetic and vasoactive drugs, volume of fluid supplementation, surgical time and volume of intraoperative hemorrhage. No patient developed significant perioperative cardiovascular complications.

General clinical and vascular parameters. The tramadol and placebo groups demonstrated similar blood flow and reactive hyperemia at all four time points. At $2 \mathrm{~h}$ postoperatively, the blood pressure and heart rate were significantly higher in the two groups compared with these values at the other three time points $(\mathrm{P}<0.05)$. In addition, at $2 \mathrm{~h}$ postoperatively, the blood flow was significantly greater in comparison with that at baseline in the two groups $(\mathrm{P}<0.05)$, whereas reactive hyperemia was significantly lower $(\mathrm{P}<0.01)$, although shear rate remained unchanged. The tramadol and placebo groups demonstrated stable responses to NTG throughout surgery (Table II).

FMD, NTG-induced dilation and VAS score. FMD was significantly higher in the tramadol group as compared with that in the placebo group at $2 \mathrm{~h}$ postoperatively $(6.7 \pm 1.5$ vs. $6.0 \pm 1.7 \%$; $\mathrm{P}=0.001$; Table III) and at 1 day postoperatively (7.1 \pm 1.3 vs. $6.9 \pm 1.4 \%$; $\mathrm{P}=0.03$; Fig. $2 \mathrm{~A}$ ). FMD decreased significantly between the baseline and $2 \mathrm{~h}$ postoperatively in the tramadol $(\mathrm{P}=0.002)$ and placebo groups $(\mathrm{P}<0.05$; Fig. 2B). Conversely, the VAS score increased significantly over the same period in the two groups $(\mathrm{P}<0.05)$. Since the two groups had similar FMD at baseline, this indicates that tramadol was associated 
Table II. Vascular parameters at different time points in patients receiving analgesic or placebo treatment following laparoscopic cholecystectomy.

Tramadol group

Placebo (saline) group

\begin{tabular}{|c|c|c|c|c|c|c|c|c|}
\hline \multirow[b]{2}{*}{ Parameter } & & \\
\hline & Baseline & $2 \mathrm{~h}$ & 1 day & 5 days & Baseline & $2 \mathrm{~h}$ & 1 day & 5 days \\
\hline $\begin{array}{l}\text { Systolic blood } \\
\text { pressure, } \mathrm{mmHg}\end{array}$ & $113.1 \pm 15.2$ & $124.0 \pm 24.2$ & $110.0 \pm 14.5$ & $113.1 \pm 18.0$ & $115.4 \pm 17.6$ & $124.7 \pm 15.9$ & $113.3 \pm 14.8$ & $117.1 \pm 21.1$ \\
\hline $\begin{array}{l}\text { Diastolic blood } \\
\text { pressure, } \mathrm{mmHg}\end{array}$ & $71.9 \pm 9.3$ & $75.8 \pm 15.2$ & $72.5 \pm 11.2$ & $71.8 \pm 9.5$ & $72.3 \pm 8.51$ & $76.2 \pm 10.4$ & $73.2 \pm 7.8$ & $69.8 \pm 9.3$ \\
\hline Heart rate, bpm & $75.3 \pm 6.2$ & $94.7 \pm 12.2$ & $81.7 \pm 13.9$ & $74.9 \pm 12.3$ & $72.1 \pm 9.6$ & $95.7 \pm 12.7$ & $77.4 \pm 11.6$ & $76.2 \pm 9.8$ \\
\hline Blood flow, $\mathrm{ml} / \mathrm{min}$ & $23.6 \pm 12.8$ & $29.7 \pm 9.6$ & $24.1 \pm 10.0$ & $24.4 \pm 6.7$ & $20.4 \pm 9.1$ & $29.8 \pm 7.6$ & $22.4 \pm 16.4$ & $26.9 \pm 14.8$ \\
\hline Shear rate, $\times 10^{3} / \mathrm{sec}$ & $81.2 \pm 20.8$ & $84.7 \pm 16.4$ & $80.2 \pm 25.5$ & $82.3 \pm 21.6$ & $86.0 \pm 21.9$ & $83.2 \pm 22.8$ & $81.2 \pm 19.8$ & $83.4 \pm 23.8$ \\
\hline Hyperemia, \% & $425 \pm 102$ & $389 \pm 105$ & $461 \pm 157$ & $425 \pm 102$ & $417 \pm 191$ & $396 \pm 110$ & $441 \pm 90$ & $393 \pm 123$ \\
\hline $\begin{array}{l}\text { NTG-induced } \\
\text { dilation, } \%\end{array}$ & $16.8 \pm 2.3$ & $17.2 \pm 3.1$ & $17.3 \pm 3.9$ & $18.6 \pm 2.6$ & $16.3 \pm 2.7$ & $16.4 \pm 3.2$ & $16.9 \pm 4.7$ & $17.1 \pm 3.7$ \\
\hline
\end{tabular}

Values are expressed as the mean \pm standard deviation. NTG, nitroglycerin.

A

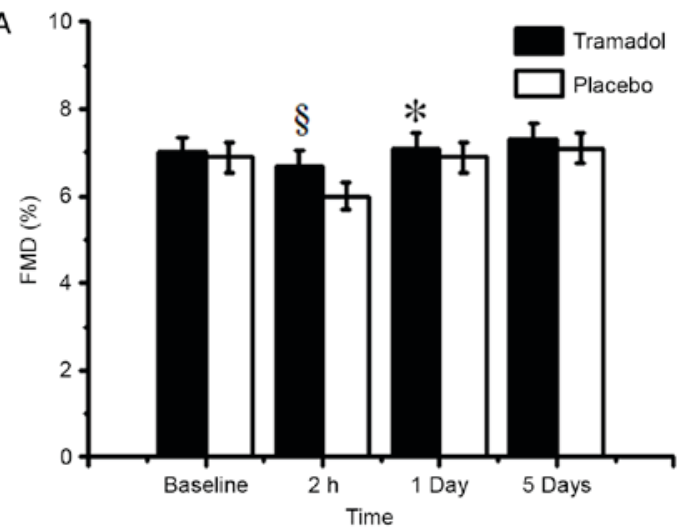

B

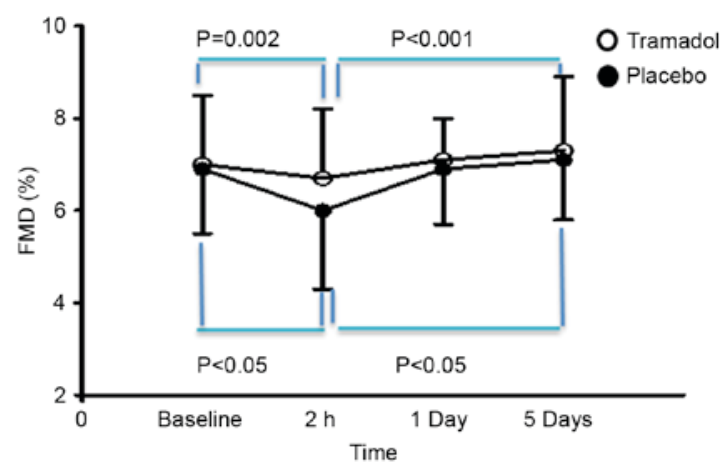

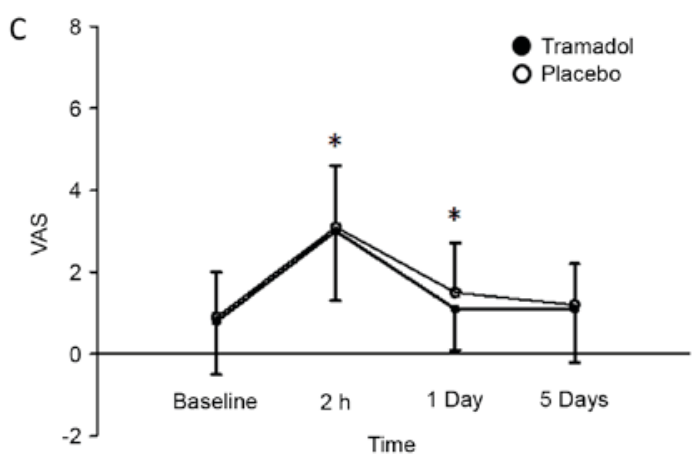

Figure 2. Comparison of brachial FMD and VAS pain score between patients in the tramadol or placebo group at the baseline and three postoperative time points. (A) Comparison of FMD. ${ }^{\S} \mathrm{P}=0.001$ and ${ }^{*} \mathrm{P}=0.015$ vs. placebo group. (B) Alterations in the brachial FMD at different time points in the two groups. (C) Comparison of VAS scores in the groups. " $\mathrm{P}<0.05$ vs. placebo group. FMD, flow-mediated dilation; VAS, visual analogue scale.

with a smaller decrease in the FMD following surgery, which later returned to similar levels for the two groups at 5 days postoperatively. Furthermore, the NTG-induced dilation were stable throughout the various time points in the two groups, ranging between $16.8 \pm 2.3$ and $18.6 \pm 2.6 \%$ in the tramadol group (P>0.20; Table II).

The VAS score was significantly lower in the tramadol group when compared with that in the placebo group at $2 \mathrm{~h}$
$(2.8 \pm 1.9$ vs. $3.2 \pm 2.3 ; \mathrm{P}=0.013)$ and 1 day postoperatively $(1.4 \pm 1.0$ vs. $1.7 \pm 1.8 ; \mathrm{P}=0.031$; Fig. $2 \mathrm{C})$. Across the two patient groups and all four time points, a VAS score of $\geq 5$ was independently associated with postoperative FMD of $<7 \%$ [odds ratio (OR), 2.7; 95\% confidence interval (95\% CI), 0.9-5.0; $\mathrm{P}=0.041]$. Conversely, a VAS score of $<5$ at $2 \mathrm{~h}$ postoperatively in the tramadol group was independently associated with an FMD value of $\geq 7 \%$ (OR, 2.5; 95\% CI, 1.0-6.0; $\mathrm{P}=0.047)$. The 
Table III. Comparison of brachial FMD and VAS scores at different times in patients receiving analgesic or placebo treatment following laparoscopic cholecystectomy.

\begin{tabular}{lccccc}
\hline & \multicolumn{2}{c}{$\begin{array}{c}\text { Tramadol } \\
\text { group }\end{array}$} & & \multicolumn{2}{c}{$\begin{array}{c}\text { Placebo } \\
\text { (saline) } \\
\text { group }\end{array}$} \\
\cline { 2 - 3 } \cline { 5 - 6 } Time point & VAS & FMD $(\%)$ & & VAS & FMD (\%) \\
\hline $\begin{array}{l}\text { Preoperative } \\
\text { day 1 }\end{array}$ & $0.8 \pm 1.3$ & $7.0 \pm 1.5$ & $0.6 \pm 1.1$ & $6.9 \pm 1.4$ \\
Postoperative & & & & & \\
2 h & $3.0 \pm 1.7$ & $6.7 \pm 1.5$ & & $3.1 \pm 1.5$ & $6.0 \pm 1.7^{\mathrm{a}}$ \\
Day 1 & $1.1 \pm 1.0$ & $7.1 \pm 0.9$ & & $1.1 \pm 1.2$ & $6.9 \pm 1.2^{\mathrm{b}}$ \\
Day 5 & $1.1 \pm 1.3$ & $7.3 \pm 1.6$ & $0.9 \pm 1.0$ & $7.1 \pm 1.3$ \\
\hline
\end{tabular}

${ }^{\mathrm{a}} \mathrm{P}=0.001$ and ${ }^{\mathrm{b}} \mathrm{P}<0.05$ vs. placebo group. Values are expressed as the mean \pm standard deviation. VAS scores were between 0 and 10. FMD, flow-mediated dilation; VAS, visual analogue scale.

total fentanyl consumption was also significantly lower in the tramadol group in comparison with that in the placebo group (37.4 \pm 36.8 vs. $53.7 \pm 37.1 ; \mathrm{P}<0.05)$.

Backward stepwise multiple linear regression identified several independent correlations between the clinicodemographic variables and FMD value of patients at $2 \mathrm{~h}$ postoperatively (Table IV). The FMD value was found to be negatively correlated with the age $(\mathrm{B}=-1.403$; $\mathrm{P}=0.011)$, VAS score $(\mathrm{B}=-0.579 ; \mathrm{P}=0.003)$ and $\mathrm{BMI}$ of patients $(\mathrm{B}=-0.551$; $\mathrm{P}=0.010$ ). In addition, the FMD at $2 \mathrm{~h}$ postoperatively was positively correlated with the FMD at the baseline $(B=1.186$; $\mathrm{P}<0.001)$.

\section{Discussion}

The results of the present relatively small randomized, double-blind trial suggested that analgesic treatment following laparoscopic cholecystectomy may lead to improved arterial endothelial function postoperatively. In addition, this improved endothelial function appears to be correlated with a lower incidence of MI. In particular, a VAS score of $<5$ appeared to be associated with a lower risk of MI.

In the present study on laparoscopic cholecystectomy, the FMD in the two groups significantly decreased below the baseline value at $2 \mathrm{~h}$ postoperatively and remained at low levels for at least 1 extra day, showing recovery at 5 days postoperatively. This timescale of postoperative FMD alterations is consistent with studies examining other types of non-cardiac surgery $(11,18,24,25)$. For instance, FMD decreased significantly compared with the baseline value during the first $24 \mathrm{~h}$ after knee replacement surgery, recovering to the baseline levels by 7 days postoperatively (18). In addition, endothelial function significantly improved in patients within 2 weeks postoperatively following renal transplant surgery (24), and 28 days after femoropopliteal bypass surgery (25). These past and present findings are consistent with the hypothesis that alterations in the arterial endothelial function during the
Table IV. Correlation analysis to identify the predictors of FMD $(\%)$ at $2 \mathrm{~h}$ postoperatively in all patients.

\begin{tabular}{lccr}
\hline Factor & B-value & $\beta$ & P-value \\
\hline Age & -1.403 & -0.913 & 0.011 \\
VAS score & -0.579 & -0.996 & 0.003 \\
Baseline FMD (\%) & 1.186 & 0.998 & $<0.001$ \\
BMI & -0.551 & -0.992 & $<0.001$ \\
Hyperemia (\%) & 0.005 & 0.17 & 0.066 \\
\hline
\end{tabular}

VAS scores were between 0 and 10. BMI, body mass index; FMD, flow-mediated dilation; VAS, visual analogue scale.

perioperative period contribute to perioperative myocardial infarction and other cardiovascular events, since these events usually occur within 3 days after surgery (26). The current study observed that the FMD level was significantly improved at $2 \mathrm{~h}$ postoperatively in the tramadol group as compared with that in the placebo group, suggesting that analgesic treatment may improve the arterial endothelial function and thereby reduce the risk of MI.

Tramadol may exert these effects by reducing the stress response to surgery and pain $(14,15)$. Perioperative trauma and pain cause stress reactions, as well as the release of proinflammatory cytokines, including C-reactive protein, tumor necrosis factor $\alpha$, interleukin (IL)-1, IL-6 and IL-8. Stress reactions and proinflammatory cytokines may then inhibit the FMD by impairing nitric oxide production (11,27-29). Indeed, IL-6 is a marker of endothelial dysfunction, and elevated levels of this cytokine are associated with a low FMD in patients suffering from myocardial infarction (29). Thoracic epidural analgesia can reduce the stress responses to surgery and pain by blocking the neuroendocrine pathway (14). Micromolar concentrations of morphine inhibit the lipopolysaccharide-induced synthesis of IL-6 (30). However, even in patients receiving pain relief by tramadol through a patient-driven system, the FMD at $2 \mathrm{~h}$ postoperatively was significantly lower compared with the baseline level, supporting the hypothesis that arterial endothelial dysfunction in the early postoperative period may help drive MI. It is possible that the MI observed in the tramadol group in the current study was due to 'non-obstructive' vulnerable plaques (2). These plaques cannot be detected by myocardial studies to investigate whether postoperative VAS scores of $\geq 5$ may be a predictor of MI following non-cardiac surgery.

The present study has several limitations. Larger sample sizes and higher-risk cohorts should be examined in the longer term in order to fully explore the correlation of analgesic treatment and endothelial function with postoperative cardiovascular complications. In addition, whether the included patients took off-study drugs, antibiotics, vitamins, potassium chloride or other antihemorrhagic treatment cannot be excluded, which may have influenced the endothelial function and therefore interfered with our results. However, it was confirmed that the tramadol and placebo groups were similar in terms of the dose and type of anesthetic and vasoactive drugs, surgery duration and clinicodemographic characteristics. 
In conclusion, the present study suggested that analgesic treatment was able to improve arterial endothelial function following non-cardiac surgery. This strengthens the previously described link between postoperative pain and vascular endothelial function; postoperative pain could impair endothelial function, leading to postoperative MI. This could inform a new treatment approach to decrease the incidence of postoperative acute coronary syndrome. More prospective work on large cohorts is needed to confirm this.

\section{References}

1. Khan J, Alonso-Coello P and Devereaux PJ: Myocardial injury after noncardiac surgery. Curr Opin Cardiol 29: 307-311, 2014

2. McIlroy DR, Chan MT, Wallace SK, Symons JA, Koo EG, Chu LC and Myles PS: Automated preoperative assessment of endothelial dysfunction and risk stratification for perioperative myocardial injury in patients undergoing non-cardiac surgery. $\mathrm{Br}$ J Anaesth 112: 47-56, 2014.

3. Deveraux PJ, Goldman L, Cook DJ, Gilbert K, Leslie K and Guyatt GH: Perioperative cardiac events in patients undergoing non-cardiac surgery: A review of the magnitude of the problem the pathophysiology of the events and methods to estimate and communicate risk. CMAJ 173: 627-634, 2005.

4. Søndergaard ES, Fonnes S and Gögenur I: Endothelial dysfunction after non-cardiac surgery: A systematic review. Acta Anaesthesiol Scand 59: 140-146, 2015.

5. Kwok T, Chook P, Tam L, Qiao M, Woo JLF, Celermajer DS and Woo KS: Vascular dysfunction in Chinese vegetarians: an apparent paradox. J Am Coll Cardiol 46: 1957-1958, 2005.

6. Fuster V, Badimon L, Badimon JJ and Chesebro JH: The pathogenesis of coronary artery disease and the acute coronary syndromes (2). N Engl J Med 326: 310-318, 1992.

7. Suwaidi JA, Hamasaki S, Higano ST, Nishimura RA, Holmes DR Jr and Lerman A: Long-term follow-up of patients with mild coronary artery disease and endothelial dysfunction. Circulation 101: 948-954, 2000.

8. Schachinger V, Britten MB and Zeiher AM: Prognostic impact of coronary vasodilator dysfunction on adverse long-term outcome of coronary heart disease. Circulation 101: 1899-1906, 2000.

9. Gokce N, Keaney JF Jr, Hunter LM, Watkins MT, Menzoian JO and Vita JA: Risk stratification for postoperative cardiovascular events via noninvasive assessment of endothelial function: A prospective study. Circulation 105: 1567-1572, 2002.

10. Gokce N, Keaney JF Jr, Hunter LM, Watkins MT, Nedeljkovic ZS, Menzoian JO and Vita JA: Predictive value of noninvasively determined endothelial dysfunction for long-term cardiovascular events inpatients with peripheral vascular disease. J Am Coll Cardiol 41: 1769-1775, 2003.

11. Hu YJ, Wei AN, Chook P, Yin Y, Cheng W, Wu MJ, Celermajer DS and Woo KS: Impact of on-cardiovascular surgery on reactive hyperaemia and arterial endothelial function. Clin Exp Pharmacol Physiol 40: 466-472, 2013.

12. Drenger B, Fontes ML, Miao Y, Mathew JP, Gozal Y, Aronson S, Dietzel $C$ and Mangano DT; Investigators of the Ischemia Research and Education Foundation; Multicenter Study of Perioperative Ischemia Research Group: Patterns of use of perioperative angiotensin-converting enzyme inhibitors in coronary artery bypass graft surgery with cardiopulmonary bypass: Effects on in-hospital morbidity and mortality. Circulation 126: 261-269, 2012.

13. Mangano DT, Siliciano D, Hollenberg M, Leung JM, Browner WS, Goehner P, Merrick S and Verrier E: Postoperative myocardial ischemia. Therapeutic trials using intensive analgesia following surgery. The Study of Perioperative Ischemia (SPI) Research Group. Anesthesiology 76: 342-353, 1992.
14. Wink J, Veering BT, Aarts LP and Wouters PF: Effect of increasing age on the haemodynamic response to thoracic epidural anaesthesia: An observational study. Eur J Anaesthesiol 31: 597-605, 2014.

15. Guo W, Liu F, Fu L, Qu R, Wang G and Zhang C: Effects of high thoracic epidural sympathetic blockade for the treatment of severe chronic heart failure due to dilated cardiomyopathy. Acta Cardiol 67: 533-539, 2012.

16. Kim JY, Park SY, Chang HS, Nam SK and Min SK: The efficacy of the time-scheduled decremental continuous infusion of fentanyl for postoperative patient-controlled analgesia after total intravenous anesthesia. Korean J Anesthesiol 65: 544-551, 2013.

17. de Boer AG, van Lanschot JJ, Stalmeier PF, van Sandick JW, Hulscher JB, de Haes JC and Sprangers MA: Is a single-item visual analogue scale as valid, reliable and responsive as multi-item scales in measuring quality of life? Qual Life Res 13: 311-320, 2004.

18. Bukal K, Ruzić A, Bazdarić K, Sokolić J, Vukić-Dugac A, Velcić-Brumnjak S, Sestan B, Gulan JR and Gulan G: Total knee replacement surgery is followed by transitory endothelial dysfunction. Coll Antropol 36: 611-616, 2012.

19. Park JK, Cheong SH, Lee KM, Lim SH, Lee JH, Cho K, Kim MH and Kim HT: Does dexmedetomidine reduce postoperative pain after laparoscopic cholecystectomy with multimodal analgesia? Korean J Anesthesiol 63: 436-440, 2012.

20. Jabbour-Khoury SI, Dabbous AS, Gerges FJ, Azar MS, Ayoub CM and Khoury GS: Intraperitoneal and intravenous routes for pain relief in laparoscopic cholecystectomy. JSLS 9: 316-321, 2005.

21. Celermajer DS, Sorensen KE, Georgakopoulos D, Bull C, Thomas O, Robinson J and Deanfield JE: Cigarette smoking is associated with dose-related and potentially reversible impairment of endothelium-dependent dilation in healthy young adults. Circulation 88: 2149-2155, 1993.

22. Woo KS, Yip TW, Chook P, Kwong SK, Szeto CC, Li JK, Yu AW, Cheng WK, Chan TY, Fung KP and Leung PC: Cardiovascular Protective Effects of Adjunctive Alternative Medicine (Salvia miltiorrhiza and Pueraria lobata) in High-Risk Hypertension. Evid Based Complement Alternat Med 2013: 132912, 2013.

23. Woo KS, Chook P, Leong HC, Huang XS and Celermajer DS: The impact of heavy passive smoking on arterial endothelial function in modernized Chinese. J Am Coll Cardiol 36: 1228-1232, 2000.

24. Kocak H, Ceken K, Yavuz A, Yucel S, Gurkan A, Erdogan O, Ersoy F, Yakupoglu G, Demirbas A and Tuncer M: Effect of renal transplantation on endothelial function in haemodialysis patients. Nephrol Dial Transplant 21: 203-207, 2006.

25. Unal O, Karatepe O, Ugurlucan M, Koc B, Filizcan U and Aksoy M: Effects of lower extremity revascularization on the endothelial functions measured with noninvasive brachial artery flow-mediated dilatation. Ann Vasc Surg 25: 969-974, 2011.

26. Fleischmann KE, Goldman L, Young B and Lee TH: Association between cardiac and noncardiac complication in patients undergoing noncardiac surgery. Outcomes and effects on length of stay. Am J Med 115: 515-520, 2003.

27. Bhagat $\mathrm{K}$ and Vallance P: Inflammatory cytokines impair endothelium-dependent dilatation in human veins in vivo. Circulation 96: 3042-3047, 1997.

28. Chia S, Qadan M, Newton R, Ludlam CA, Fox KA and Newby DE: Intra-arterial tumor necrosis factor-alpha impairs endothelium-dependent vasodilatation and stimulates local tissue plasminogen activator release in humans. Arterioscler Thromb Vasc Biol 23: 695-3701, 2003.

29. Erzen B, Sabovic M, Sebestjen M, Keber I and Poredos P: Interleukin-6 correlates with endothelial dysfunction in young post-myocardial infarction patients. Cardiology 107: 111-116, 2007.

30. Roy S, Cain KJ, Chapin RB, Charboneau RG and Barke RA: Morphine modulates NF kappa B activation in macrophages. Biochem Biophys Res Commun 245: 392-396, 1998. 